\title{
Water vole (Arvicola amphibius) abundance in grassland habitats of Glasgow
}

\author{
R.A. Stewart ${ }^{1}$, C. Jarrett ${ }^{1}$, C. Scott ${ }^{2}$, S.A. White ${ }^{1} \&$ D.J. McCafferty ${ }^{3}$ \\ ${ }^{1}$ Institute of Biodiversity, Animal Health and Comparative Medicine, College of Medical, Veterinary and Life \\ Sciences, University of Glasgow, G12 8QQ, Scotland, UK \\ ${ }^{2}$ Land and Environmental Services, Glasgow City Council, 231 George Street, Glasgow, G1 1RX, Scotland, UK \\ ${ }^{3}$ Scottish Centre for Ecology and the Natural Environment, Institute of Biodiversity, Animal Health and Comparative \\ Medicine, College of Medical, Veterinary and Life Sciences, Rowardennan, Glasgow, G63 0AW, Scotland, UK \\ ${ }^{1}$ E-mail: robyn.stewart@glasgow.ac.uk
}

\begin{abstract}
Water vole (Arvicola amphibius) populations have undergone a serious decline throughout the UK, and yet a stronghold of these small mammals is found in the greater Easterhouse area of Glasgow. The water voles in this location are mostly fossorial, living a largely subterranean existence in grasslands, rather than the more typical semi-aquatic lifestyle in riparian habitats. In this study, we carried out capture-mark-recapture surveys on water voles at two sites: Cranhill Park and Tillycairn Drive. We made a total of 62 captures including retraps, and the resulting population estimates were 78 individuals (95\% confidence interval 41-197) for Cranhill Park and 42 individuals (20-141) for Tillycairn Drive. From these figures we estimated a population density of water voles, which appeared to be higher than other reports from the UK. Despite the difficulties of sampling in urban environments that resulted in relatively low capture rates, our data suggest that the greater Easterhouse area of Glasgow holds water voles at relatively high population densities. These results will inform future conservation in the City of Glasgow and surrounding areas, as well as raise awareness of important water vole populations in urban environments.
\end{abstract}

\section{INTRODUCTION}

Water voles have suffered severe declines in the UK due to habitat fragmentation, industrialisation, intensification of agricultural practices and predation from American mink (Neovison vison) (Strachan, 2004). Consequently, water voles are protected in the UK under the Wildlife and Countryside Act 1981 (Strachan, 2004). Approximately $40 \%$ of the UK water vole population is thought to reside in Scotland with the majority of water vole colonies found as upland metapopulations (i.e. discrete colonies maintained by frequent immigration and emigration events from nearby colonies), which are spread across the Cairngorm mountain range and Assynt (Stewart et al., 1998; Capreolus Wildlife Consultancy, 2005). In the UK the distribution of water voles is almost exclusively associated with riparian habitats.

Riparian water vole populations consist of multiple breeding units strung-out along the length of the water course with females being the territorial sex during the breeding season, demarcating the area with piles of droppings (latrines) and actively excluding other females, in contrast to the larger home range of the males (Strachan \& Moorhouse, 2006). The length of habitat occupied is dependent on population density with mean territory size measuring $30-150 \mathrm{~m}$ for females and 60-300 $\mathrm{m}$ for male home ranges at high and low densities, respectively (Strachan \& Moorhouse, 2006). The mating season is triggered by increasing day length in early spring and extends from March through to September (Strachan \& Moorhouse, 2006), although breeding as early as February has been documented (Stoddart, 1970). On average, females give birth to five to eight offspring and have multiple litters throughout the breeding season. Life expectancy can reach three years but a lifespan of twelve months is more common. Water vole populations are subject to high over-winter mortality rates averaging 64\% (Carter \& Bright, 2003), but reaching as high as $70 \%$ of animals (Strachan \& Moorhouse, 2006).

For some time there has been confusion over the exact habitat preference of water voles, particularly because suitable sites will often go unoccupied (Lawton \& Woodroffe, 1991). It is widely accepted, however, that established colonies require a length of continuous riparian habitat, slow-flowing water, soft banks for burrowing, and dense vegetation for both cover and food (Lawton \& Woodroffe, 1991; Aars et al., 2001; Telfer et al., 2001; Lambin et al., 2004; Fischer et al., 2009). Habitats subject to heavy grazing, trampling or overshading by trees are actively avoided (Strachan \& Moorhouse, 2006). The length of riparian habitat required varies between lowland and upland populations, largely because of habitat quality, with lowland colonies occupying lengths of 100-400 m (Lawton \& Woodroffe, 1991) and upland colonies occupying lengths $50-700 \mathrm{~m}$, although length varies between years (Capreolus Wildlife Consultancy, 2005).

However, elsewhere in Europe water voles are also found in dry grassland habitats and are regarded as fossorial. Water voles found in dry grassland favour upland meadows and can be found at high population densities in mountain regions (Berthier et al., 2014). Distribution is not limited by water features and burrow 
systems can exceed $100 \mathrm{~m}$ in length in a complex array of runs, nest chambers, food stores and bolt holes and will usually house a single breeding unit, a male and female, with their offspring (Meylan, 1977). Their existence is almost exclusively subterranean, foraging for rhizomes, tubers and fleshy roots along the runs (Meylan, 1977). Plugging up entrance holes with soil is a well-documented behaviour (Meylan, 1977), as is the creation of above ground soil mounds, termed tumuli, a by-product of digging activity (Giraudoux et al., 1995).

Fossorial populations can become a serious pest in some areas due to the economic impact they can have on agricultural crops and orchards by damaging root systems, consuming plants and digging extensive burrow systems which can destabilize soil structure (Meylan, 1977). Giraudoux et al. (1995) noted that in peak years populations were forced to expand into surrounding habitats even if they were unfavourable. Regulation of the population is thought to be largely down to density-dependent factors such as food availability and disease (Saucy, 1994).

It was initially thought that only riparian water voles occurred in Britain (Corbet \& Harris, 1991). Historically dry grassland populations have been reported for only a few locations in the UK, on island locations in Scotland and Reads Island in the Humber Estuary (Strachan \& Moorhouse, 2006). Telfer et al. (2003) also identified large populations of fossorial water voles on a number of small islands in the Sound of Jura. In 2008 water voles were reported to occur in dry grassland habitats in the greater Easterhouse area of Glasgow, occupying a variety of sites including public parks, gardens, vacant and derelict land and road verges (Fig. 1; Stewart et al., 2017). The unusual characteristic of the water vole population here, aside from its fossorial habitat, is the high degree of urbanisation in the surrounding area. The importance of urban areas for water voles is beginning to be considered in the literature; for instance Brzeziński et al. (2018) document the use of urban areas as refuges for water voles, as their main predator American mink appear to avoid built-up habitats.

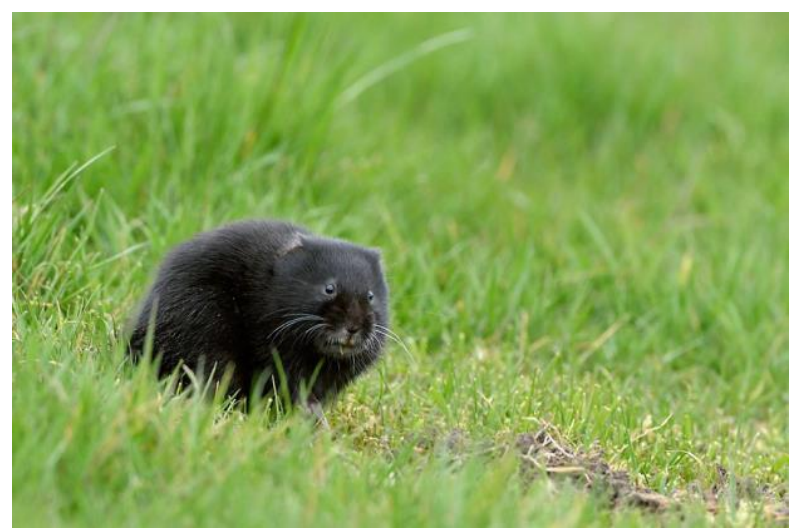

Fig. 1. Fossorial water vole (Arvicola amphibius), Cranhill Park, Glasgow, April 2017. (Photo: L. Campbell)
The fossorial water vole populations of the greater Easterhouse area of Glasgow face the constant threat of expanding urbanisation. Areas which until now have been vacant and derelict land suitable for water voles are in many cases the chosen sites for urban development, such as social housing. These development projects, though of great benefit to the community, require mitigation strategies for the water vole populations and Glasgow City Council is currently developing a Water Vole Conservation Strategy in partnership with a range of organisations including Scottish Natural Heritage (SNH) and the Seven Lochs Wetland Park (Glasgow City Council, pers. comm.). Management options for conserving water voles in prospective development sites include planning design which retains populations in situ, displacing animals into areas of newly created adjacent habitat and within and between-site relocation by trapping (Dean et al., 2016). To successfully carry out these management options, it is necessary to have an estimation of the population size at each site.

Various techniques have been used previously in order to estimate the abundance of water vole populations, including surveying for field signs (Telfer et al., 2001; Berthier et al., 2014), and by capture-mark-recapture (CMR) studies (Telfer et al., 2003), although most population estimations have been undertaken in riparian habitats. Previous work in Glasgow included field sign surveys, but no significant relationship was found between the abundance of field signs and water vole density (Stewart et al., 2017; see the Appendix for a guide to identifying field signs). Therefore, the aim of this study was to carry out a more detailed estimation of the abundance of water voles occupying dry grassland habitats in the greater Easterhouse area of Glasgow.

\section{MATERIAL AND METHODS Trapping}

Trapping was conducted at two sites: Cranhill Park (55'51'48.53”N, 4'10'06.27'W) and Tillycairn Drive (55'52'28.48'N, 408'56.41'W) in July and August 2015 (Fig. 2). Each trapping session was conducted over a five-day period with traps installed on the first day and left unset for approximately 24 hours. Trapping was conducted twice at Cranhill Park (denoted as Cranhill 1 and Cranhill 2) and once at Tillycairn Drive, but, due to some traps being stolen and problems with access to sites, trapping hours varied between Cranhill (July: 728 total trap hours; August 600 trap hours) and Tillycairn (July to August: 960 trap hours). Two types of traps were used: Sherman Folding Traps (model XLK, H.B Sherman Traps Inc., https://www.shermantraps.com) and specially constructed tube traps based on a simple design from a German trap (Rohrenfalle), used for trapping fossorial water voles and moles (D. Gow, pers. comm.). The tube traps were constructed from grey plastic plumbing pipe (length $30 \mathrm{~cm}$, diameter $8.5 \mathrm{~cm}$ ) with one-way hinged doors at either end. 


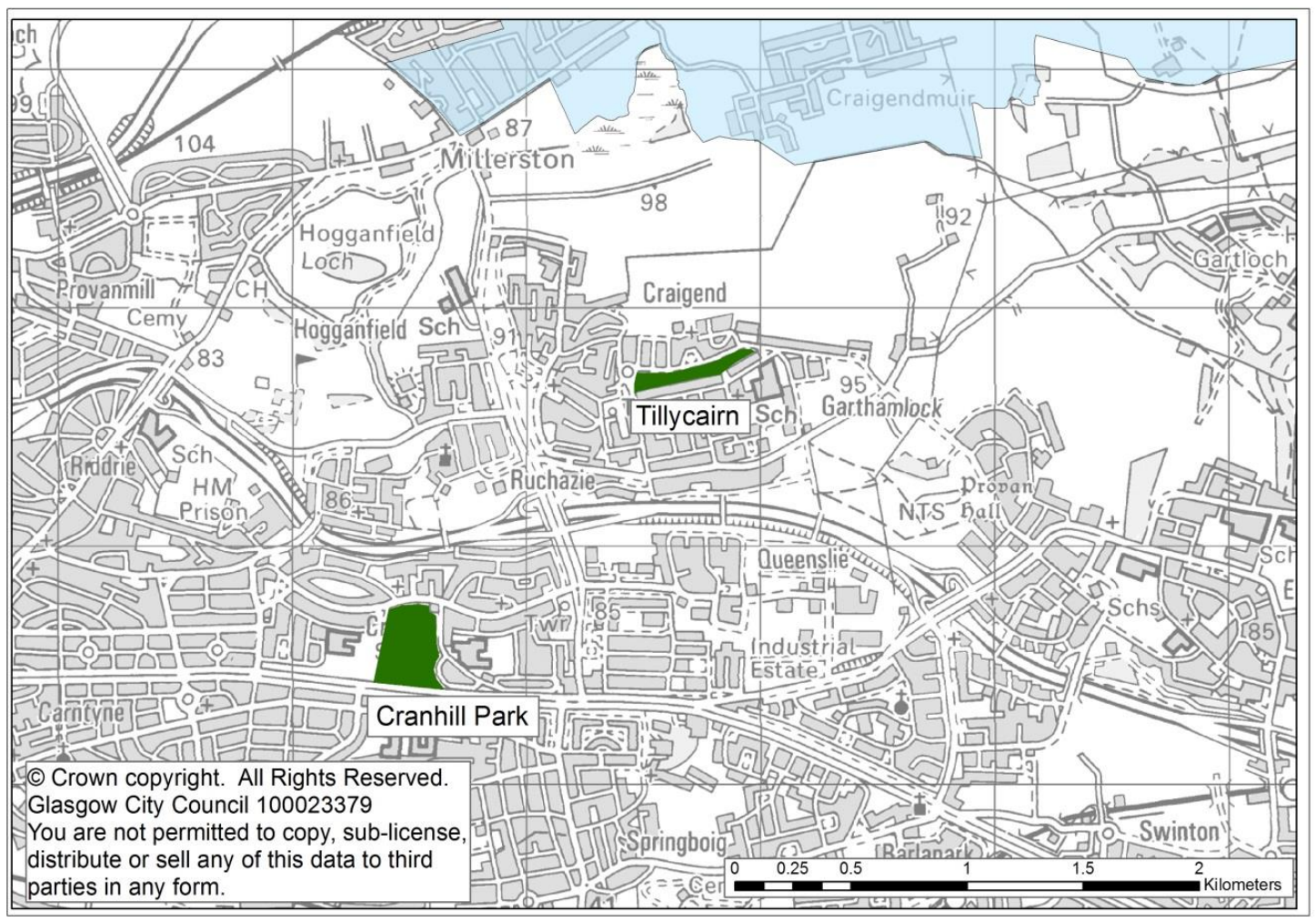

Fig. 2. Map showing location of water vole (Arvicola amphibius) trapping sites, Cranhill Park and Tillycairn Drive, in the greater Easterhouse area of Glasgow.

Paired traps were set at $10 \mathrm{~m}$ intervals along a $100 \mathrm{~m}$ transect following guidelines by Gurnell \& Flowerdew (2006) and trap positioning based on Telfer et al. (2003). The paired traps at each trapping point were set at right angles to an obvious field sign (e.g. burrow entrance) at a distance of 50-100 $\mathrm{cm}$ depending on terrain. Traps were numbered prior to use and each trapping point was marked by a marker cane. Each trap was provisioned with around $120 \mathrm{~g}$ chopped carrots and fresh hay for bedding, with a handful of chopped apple placed at the entrance of the trap as bait (Strachan \& Moorhouse, 2006). Traps were secured in position by placing them on flat ground in a water vole run or beneath a grass tussock. Once secured the traps were covered with vegetation to provide shelter, some degree of insulation and a visual barrier against predators and human interference. Traps were checked daily at 0500, 1300 and 2100, and were cleaned, re-provisioned and reset as necessary after each check. Once the five day trapping was complete, Sherman traps were autoclaved and Tube traps were disinfected.

Captured animals were transferred into a pop-up pen (Heavy Duty Polyethylene, height $58 \mathrm{~cm}$, Gardman ${ }^{\mathrm{TM}}$, http://www.gardman.co.uk; Strachan \& Moorhouse 2006). The water vole was then transferred into a cardboard tube and body mass $\pm 0.1 \mathrm{~g}$ recorded using a DIPSE PS-250 digital scale. Body length (nose to base of tail), tail length, hind foot length and anal-genital gap (to indicate sex) were recorded using a metal ruler $( \pm 0.5$ $\mathrm{mm})$. Coat colour, presence/absence of ectoparasites (e.g. gamasid mites and fleas (Siphonaptera)) and general body condition were also noted. Animals were then marked by injecting an AVID ${ }^{\text {TM }}$ Single-use Sterile Syringes PIT tag (www.avidplc.com) subcutaneously into the scruff between the shoulder blades. Following this, the animal was returned to the pen and monitored for five minutes and checked using the AVID ${ }^{\text {TM }}$ MiniTracker Microchip Scanner to ensure marking was successful before release at point of capture under a grass tussock for cover.

All trapping was carried out under Home Office Licence and with consultation from $\mathrm{SNH}$.

\section{Capture mark recapture $(\mathrm{CMR})$}

Program MARK (www.phidot.org/software/mark/) was used to model water vole population size at each site based on CMR data. We assumed a closed population with no migration or birth/deaths (and therefore a constant number of animals) for each site. Closed population "Huggins $p$ and $c$ " model was chosen where $\mathrm{N}$, the population estimate, is a derived parameter based on the number of animals detected and assumes an equal probability of capture for all individuals. This model was appropriate because of the short trapping time scale used during the breeding season with adults displaying strong site fidelity. The most parsimonious model was used in each case based on the model with the lowest corrected AIC against the highest AIC and lowest number of parameters (Stewart, 2015). The goodness of fit was tested using the variance inflation factor ( $\hat{c})$ and 120 simulations run for each model. Due to the use of linear trapping methodology in a non-linear habitat only relative abundance estimates can be calculated for the areas sampled rather than true population density. However, the length and width of each trapping site 
were measured using a $100 \mathrm{~m}$ measuring tape and the total area of each grassland patch calculated (ha) to provide an approximate density for comparison with previous studies. Areas were 0.5 ha and 0.15 ha for Cranhill Park and Tillycairn Drive, respectively.

Both trapping sites were classed as B2 (neutral grassland) according to a Phase 1 habitat survey (JNCC, 2010). All sites were urban and had sward composition resulting from varying degrees of management, for instance different frequency of grass cutting or varying fertilizer use. Cranhill Park had received the greatest amount of sward improvement compared with Tillycairn Drive due to grass cutting and the historical application of fertilisers associated with its previous use as a golf course. Sites were dominated by grass species and were low in plant species diversity. Holcus spp. were the dominant grass species at both sites with a mean percentage cover of $52 \%(\mathrm{SD}=10.6)$. Average sward height was $35 \mathrm{~cm}$ for Cranhill Park and $45 \mathrm{~cm}$ for Tillycairn Drive. Tillycairn Drive was classed according to the National Vegetation Classification (NVC; Rodwell, 1992) as MG1 Arrhenatherum elatius-Festuca rubra sub-community, a species poor community dominated by tall, tussock grasses. Sward composition could not be classified at Cranhill Park by the NVC system as species-poor grasslands dominated by $H$. lanatus and $H$. mollis do not fit into the current system (Averis, 2013).
Statistical tests were performed using the statistical programming environment $\mathrm{R}$ Version 3.3.3 (www.rproject.org).

\section{RESULTS}

Trapping

A total of 49 individual water voles were successfully trapped (45 adults and four juveniles; one adult male died on handling). Trapped individuals consisted of 31 females and 18 males, although this sex ratio difference was statistically non-significant $\left(\chi^{2}=3.45\right.$, df $=1, \mathrm{p}=$ $0.063)$. The mean body mass of voles was $109.0 \mathrm{~g}$ $(\mathrm{SE}=5.04$, range $=38.4-221.7)$. Body length and body mass were positively related (ANCOVA $F_{1,46}=67.12$ $\mathrm{p}<0.0001$; Fig. 3), but there was no difference in body mass between sexes after controlling for body length $\left(F_{1,46}=0.26 \mathrm{p}=0.55\right)$. Linear regression (both sexes combined) was: mass $(\mathrm{g})=1.7(\mathrm{SE}=0.21) *$ body length $(\mathrm{mm})-139.2$ (SE=29.93), $\left(\mathrm{F}_{1,47}=69.56 \mathrm{p}<0.0001\right)$. There was variation in coat colour with 36 , eight and five individuals with black, brown and intermediate coloured coats respectively $\left(\chi^{2}=35.80\right.$, df $=2$, $\mathrm{p}<0.0001$ ). Ectoparasites (mites and fleas) were found on 22 of the 49 individuals trapped. From a total of 62 captures (including retraps) Sherman traps were more successful, capturing 44 individuals compared to the 18 caught in tube traps $\left(\chi^{2}=10.90, \mathrm{df}=1, \mathrm{p}=0.001\right)$.

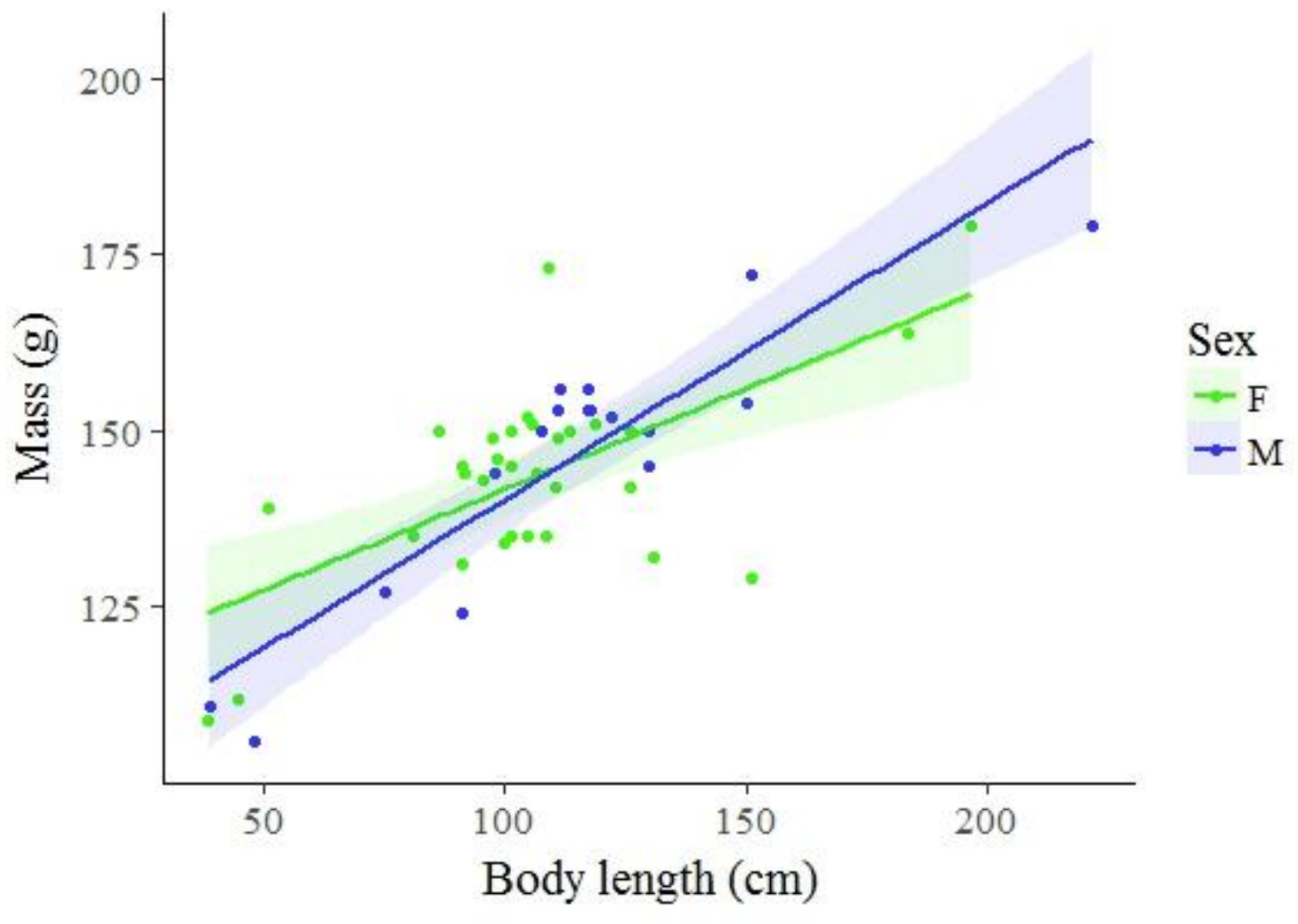

Fig. 3. Linear regression of mass ( $\mathrm{g}$ ) against body length $(\mathrm{cm})$ of all water vole (Arvicola amphibius) captures. Females (F) are represented by green points and lines, with males (M) by blue points and lines. Shaded areas indicate $95 \%$ confidence limits. 


\section{Mark-recapture}

From 48 water voles successfully marked with PIT tags there were 12 recaptures (adults: 11 female, one male). Only two animals were recaptured on multiple occasions: one female from Cranhill Park was recaptured twice and another female from Tillycairn Drive was re-trapped four times. For Cranhill 1 and Cranhill 2 the derived population estimates were 78 $(95 \% \mathrm{Cl} 41-197)$ and 42 (20-141) individuals, respectively. The Tillycairn Drive derived population estimate was six (5-10). This resulted in an estimated population density of 156 animals ha ${ }^{-1}$ (82-394), 84 (40282) and 40 (33-67) for Cranhill 1 (July), Cranhill 2 (August) and Tillycairn Drive (July-August), respectively.

\section{DISCUSSION}

Recapture rates at Cranhill Park were low, 16\% in July and $15 \%$ in August, meaning only a small percentage of the total population were marked; whereas recapture rates at Tillycairn Drive were $60 \%$ for adult water voles (juveniles were considered non-resident within the habitat patch because of the likelihood of dispersal and excluded from analysis). Indeed, the especially low recapture rates at Cranhill Park appear to be sitespecific. Aars et al. (2006) found recapture rates of 73 to $92 \%$ over a 4-day trapping period in upland Scottish populations. European fossorial water voles have in the past been found to be easily trapped with up to $70 \%$ of the population captured in the first day, but the methodology involved deliberately disturbing burrow entrances to elicit investigatory behaviour from the animal which increased ease of capture (Meylan, 1977). Telfer et al. (2003) found three days of trapping was adequate for the Sound of Jura fossorial voles but traps were set on fixed grids rather than the linear transect used in this study. The low rate of capture in Cranhill Park (and Tillycairn Drive to a lesser extent) resulted in less robust population estimates (Amstrup et al., 2005) with associated large confidence intervals.

PIT tags are a proven effective method of individually marking animals and have a high retention rate (Harper \& Batzli, 1996; Melis et al., 2011), and therefore PIT tag failure or loss was considered unlikely. Despite a trapping duration of five days being adequate for the majority of rodent populations (Gurnell \& Flowerdew, 2006), future studies with water voles in Glasgow should consider a more extensive trapping period if trapping rate is low. However, extended trapping periods in urban environments will inherently carry more risk of disruption. Indeed this study was disrupted on multiple occasions: traps were interfered with, stolen, and dogs were witnessed attempting to dig out animals all of which are potentially wildlife crimes. These events, rarely encountered outside urban areas, could partially explain the low capture rate of the east Glasgow water voles.

In this study, estimated water vole abundance ranged from around 40 to $156 \mathrm{ha}^{-1}$ across the two sites. Due to the limitations of working in public parkland, linear transects were used to give an approximate water vole abundance based on the area of habitat covered by the transect line. Additionally, the models created using the programme MARK assume a closed population, whilst it is likely that there is connectivity between sites in the water vole populations of the greater Easterhouse area. Nevertheless, these estimates suggest relatively high abundance compared with other sites in UK. Water vole abundance varies seasonally and across years and from previous studies in the UK densities of 40 to 50 animals $\mathrm{ha}^{-1}$ have been recorded in reed beds (Strachan \& Moorhouse, 2006), while the fossorial populations of Scottish Islands had an average density of $26 \mathrm{ha}^{-1}$, increasing to $70 \mathrm{ha}^{-1}$ in Spring (Telfer et al., 2003) which indicates that the water vole density found at Cranhill Park appears to be one of the highest recorded in the UK. In continental Europe fossorial populations oscillate with a four to eight year cycle and in peak years water vole numbers can reach "outbreak" densities of 1,000 ha-1 (Meylan, 1977; Giraudoux et al., 1995; Weber et al., 2002; Berthier et al., 2014). A mean population density of $476 \mathrm{ha}^{-1}$ (range 80-900 ha-1) has been reported for fossorial water voles in Jura Mountains of Switzerland (Weber \& Aubrey, 1993).

Linear trapping along a transect line is a wellestablished sampling technique for many small mammal species (Gurnell \& Flowerdew, 2006) and is the standard methodology for riparian populations of water voles (Strachan et al., 2011). In this study, linear sampling was adopted because of cost constraints and concerns over sampling in the urban environment, and while it proved an effective method for initial research, sampling on a grid square pattern similar to that used by Telfer et al. (2003) would be recommended for any future work. Sampling on a grid pattern would also allow for the collection of information on individual spatial movements and provide insight into home range size. Whilst this study was only part of a pilot study and further work is required, our results do indicate that grassland water vole home ranges can be small at high population densities. The mean range size of water voles has been shown to decrease in response to higher quality foraging (Moorhouse \& MacDonald, 2008), therefore it is possible that considerably smaller home range sizes can be supported in grasslands compared to riparian habitats.

Water voles trapped during this study had a mean body mass of $109 \mathrm{~g}$, lower than previously recorded body size of 140-350 g in UK (Strachan et al., 2011). However, given the small sample size and wide variation (range 38.4-221.7 g), and the likelihood that trapping included a number of sub-adults, we are reluctant to derive any conclusions on the body size of the east Glasgow water voles. Additionally, we captured a number of large males that reached a maximum body mass of $221.7 \mathrm{~g}$. European fossorial water voles tend to be smaller in size but the range of 60-150 g quoted by Saucy (1994) could actually be for A. scherman rather than A. amphibius because it pre-dates Panteleyev's (2001) separation of the species based on morphological adaptations. The biometrics of fossorial east Glasgow water voles should be directly compared with those of neighbouring 
riparian populations to investigate this fully. Juveniles were trapped only at Tillycairn, which is most likely due to the timing of trapping (28th July to 1st August) coinciding with the time of dispersal of the newly emerged juveniles (Strachan \& Moorhouse, 2006).

This study is the first use of capture-mark-recapture in estimating population size of the fossorial water voles in the greater Easterhouse area of Glasgow. Our results suggest, despite low capture rates, that population densities of water voles are high, perhaps more comparable to continental European water vole populations than to riparian populations in the UK. These findings underline the importance of management strategies to allow water vole populations to persist despite expanding urban areas. Indeed, Glasgow City Council is pioneering a proactive conservation strategy for water voles, creating a "green network" of sites across the greater Easterhouse area, with the hope of allowing water vole populations to persist, despite the loss of some of their habitat. Future research will necessarily involve further population surveys, in order to optimise management strategies for fossorial water voles of this area. We also hope that the provision of a guide to identifying field signs (see Appendix) will encourage other workers to study fossorial water voles at other locations.

\section{ACKNOWLEDGEMENTS}

We gratefully acknowledge support from D. Marshall (Land and Environment Services, Glasgow City Council), John Shelton and Shelagh MacMillan (Scottish Natural Heritage, SNH), S. Scott, S. Porch, Scottish Badgers Group, Cranhill Community Centre, Glasgow Countryside Rangers and Glasgow Community Safety Officers kindly assisted with fieldwork. Expertise was also provided by C. Balling (JDC Ecology), S. Babayan, P. Johnson, J. Laurie, P. McLaughlin (IBAHCM, University of Glasgow). Thanks also to M. Oliver, S. Telfer and E. Bryce (University of Aberdeen) for advice on trapping. Funding for the project was provided by Glasgow City Council, Scottish Natural Heritage and Glasgow Natural History Society. Trapping was conducted under Home Office Licence. This project was undertaken by R. Stewart in fulfilment of a Master of Research at the University of Glasgow.

\section{REFERENCES}

Aars, J., Lambin, X., Denny, R., \& Griffin, A. (2001). Water vole in the Scottish uplands: distribution patterns of disturbed and pristine populations ahead and behind the American mink invasion front. Animal Conservation 4, 187-194. https://doi.org/10.1017/S1367943001001226

Aars, J., Dallas, J.F., Piertney, B., Marshall, F., Gow, J.L., Telfer, S. \& Lambin, X. (2006). Widespread gene flow and genetic variability in populations of water voles Arvicola terrestris in patchy habitats. Molecular Ecology 15, 1455-1466. https://doi.org/10.1111/j.1365-294X.2006.02889.x
Amstrup, S.C., McDonald, T.L. \& Manly, B.F.J. (2005). Handbook of Capture-Recapture Analysis. Princeton University Press, Princeton, USA.

Averis, B. (2013). Plants and Habitats: An Introduction to Common Plants and their Habitats in Britain and Ireland. Ben Averis, UK.

Berthier, K., Piry, S., Cosson, J-F., Foltete, J-C., Defaut, R., Truchetet, D. \& Lambin, X. (2014). Dispersal, landscape and travelling waves in cyclic vole populations. Ecology Letters 17, 53-64. https://doi.org/10.1111/ele.12207

Brzeziński, M., Ignatiuk, P., Żmihorski, M. \& Zalewski, A. (2018). An invasive predator affects habitat use by native prey: American mink and water vole co-existence in riparian habitats. Journal of Zoology 304, 109-116. https://doi.org/10.1111/jzo.12500

Capreolus Wildlife Consultancy (2005). The Ecology and Conservation of Water Voles in Upland Habitats. Scottish Natural Heritage Commissioned Report No. 099 (ROAME No. F99AC320).

Carter, S.P. \& Bright, P.W. (2003). Reedbeds as refuges for water voles (Arvicola terrestris) rom predation by introduced mink (Mustela vison). Biological Conservation 111, 371-376. https://doi.org/10.1016/S0006-3207(02)00305-1

Corbet, G.B. \& Harris, S. (1991). The Handbook of British Mammals (3rd Edition). Blackwell Scientific Publications, Oxford.

Dean, M., Strachan, R., Gow, D. \& Andrews, R. (2016). The Water Vole Mitigation Handbook. The Mammal Society, London.

Fischer, D.O., Lambin, X. \& Yletyinen, S.M. (2009). Experimental translocation of juvenile water voles in a Scottish lowland metapopulation. Population Ecology 51, 289-295. https://doi.org/10.1007/s10144-008-0122-4

Giraudoux, P., Pradier, B., Delattre, P., Deblay, S., Salvi, D. \& Défaut, R. (1995). Estimation of water vole abundance by using surface indices. Acta Theriologica 40, 77-96. https://doi.org/10.4098/AT.arch.95-9

Gurnell, J. \& Flowerdew, J. (2006). Live Trapping Small Mammals: A Practical Guide. The Mammal Society.

Harper, S.J. \& Batzli, G.O. (1996). Monitoring use of runways by voles with passive integrated transponders. Journal of Mammalogy 77, 364-369. https://doi.org/10.2307/1382809

JNCC (Joint Nature Conservation Committee). (2010). Handbook for Phase 1 Habitat Survey - A Technique for Environmental Audit. ISBN 0861396367.

Lambin, X., Aars, J., Piertney, S.B. \& Telfer, S. (2004). Inferring pattern and process in small mammal metapopulations: insights from ecological and genetic data. In: Hanski, I., Gaggiotti, O. (Editors). Ecology, Genetics and Evolution of Metapopulations, pp. 515-540. Academic Press, San Diego, USA. https://doi.org/10.1016/B978-012323448-3/50023-4

Lawton, J.H., \& Woodroffe, G.L. (1991). Habitat and the distribution of water voles: why are there gaps in a species' range? Journal of Animal Ecology 60, 7991. 
https://doi.org/10.2307/5446

Melis, C., Holmern, T., Ringsby, T.H. \& Saether, B-E. (2011). Who ends up in the eagle owl pellets? A new method to assess whether water voles experience different predation risk. Mammalian Biology 76, 683-686.

https://doi.org/10.1016/j.mambio.2011.06.008

Meylan, A. (1977). Fossorial forms of the water vole, Arvicola terrestris (L.) in Europe. EPPO Bulletin 7, 209-221.

https://doi.org/10.1111/j.1365-2338.1977.tb02723.x

Moorhouse, T.P. \& MacDonald, D.W. (2008). What limits male range sizes at different population densities? Evidence from three populations of water voles. Journal of Zoology 274, 395-402. https://doi.org/10.1111/j.1469-7998.2007.00399.x

Panteleyev, P.A. (2001). The Water Vole. Mode of the Species. Nauka, Moscow. http://www.iucnredlist.org/details/full/2149/0

Rodwell, J.S. (Editor). (1992). British Plant Communities. Volume 3. Grassland and Montane Communities. Cambridge University Press, Cambridge.

Saucy, F. (1994). Density dependence in time series of the fossorial form of the water vole, Arvicola terrestris. Oikos 71, 381-392. https://doi.org/10.2307/3545826

Stewart, R.A. (2015). The Ecology of the Water Vole (Arvicola amphibius) in Grassland Habitats in the City of Glasgow. $\mathrm{MSc}(\mathrm{R})$ thesis, University of Glasgow.

Stewart, R.A., Clark, T.J., Shelton, J., Stringfellow, M., Scott, C., White, S.A. \& McCafferty, D.J. (2017). Urban grasslands support threatened water voles. Journal of Urban Ecology 3. https://doi.org/10.1093/jue/jux007

Stewart, W.A., Dallas, J.F., Piertney, S.B., Marshall, F., Lambin, X. \& Tefler, S. (1998). Metapopulation genetic structure in the water vole, Arvicola terrestris, in NE Scotland. Biological Journal of the Linnaean Society 68, 159- 171. https://doi.org/10.1111/j.1095-8312.1999.tb01164.x

Stoddart, M. (1970). Individual range, dispersion and dispersal in a population of water voles (Arvicola terrestris L.). Journal of Animal Ecology 39, 403424.

https://doi.org/10.2307/2979

Strachan, R. (2004). Conserving water voles: Britain's fastest declining mammal. Water and Environment Journal 18, 1-4. https://doi.org/10.1111/j.1747-6593.2004.tb00483.x

Strachan, R. \& Moorhouse, T. (2006). Water Vole Conservation Handbook (2nd Edition). Wildlife Conservation Research Unit, University of Oxford.

Strachan, R., Moorhouse, T. \& Gelling, M. (2011). Water Vole Conservation Handbook (3rd Edition). Wildlife Conservation Research Unit, University of Oxford.

Telfer, S., Holt, A., Donaldson, R. \& Lambin, X. (2001). Metapopulation processes and persistence in remnant water vole populations. Oikos 95, 31-42. https://doi.org/10.1034/j.1600-0706.2001.950104.x
Telfer, S., Dallas, D.F., Aars, J., Piertney, S. B., Stewart, W.A. \& Lambin, X. (2003). Demographic and genetic structure of water voles (Arvicola terrestris) on Scottish islands. Journal of Zoology London 259, 23-29. https://doi.org/10.1017/S0952836902003321

Weber, J-M. \& Aubry, S. (1993). Predation by foxes, Vulpes vulpes, on the fossorial form of the water vole, Arvicola terrestris scherman, in western Switzerland. Journal of Zoology 229, 553-559. https://doi.org/10.1111/j.1469-7998.1993.tb02656.x

Weber, J-M., Aubry, S., Ferrari, N., Fischer, C., Lachat Feller, N., Meia, J-S. \& Meyer, S. (2002). Population changes of different predators during a water vole cycle in a central European mountainous habitat. Ecography 25, 95-101. https://doi.org/10.1034/j.1600-0587.2002.250111.x 


\section{APPENDIX}

Identification of fossorial grassland water vole (Arvicola amphibius) field signs.

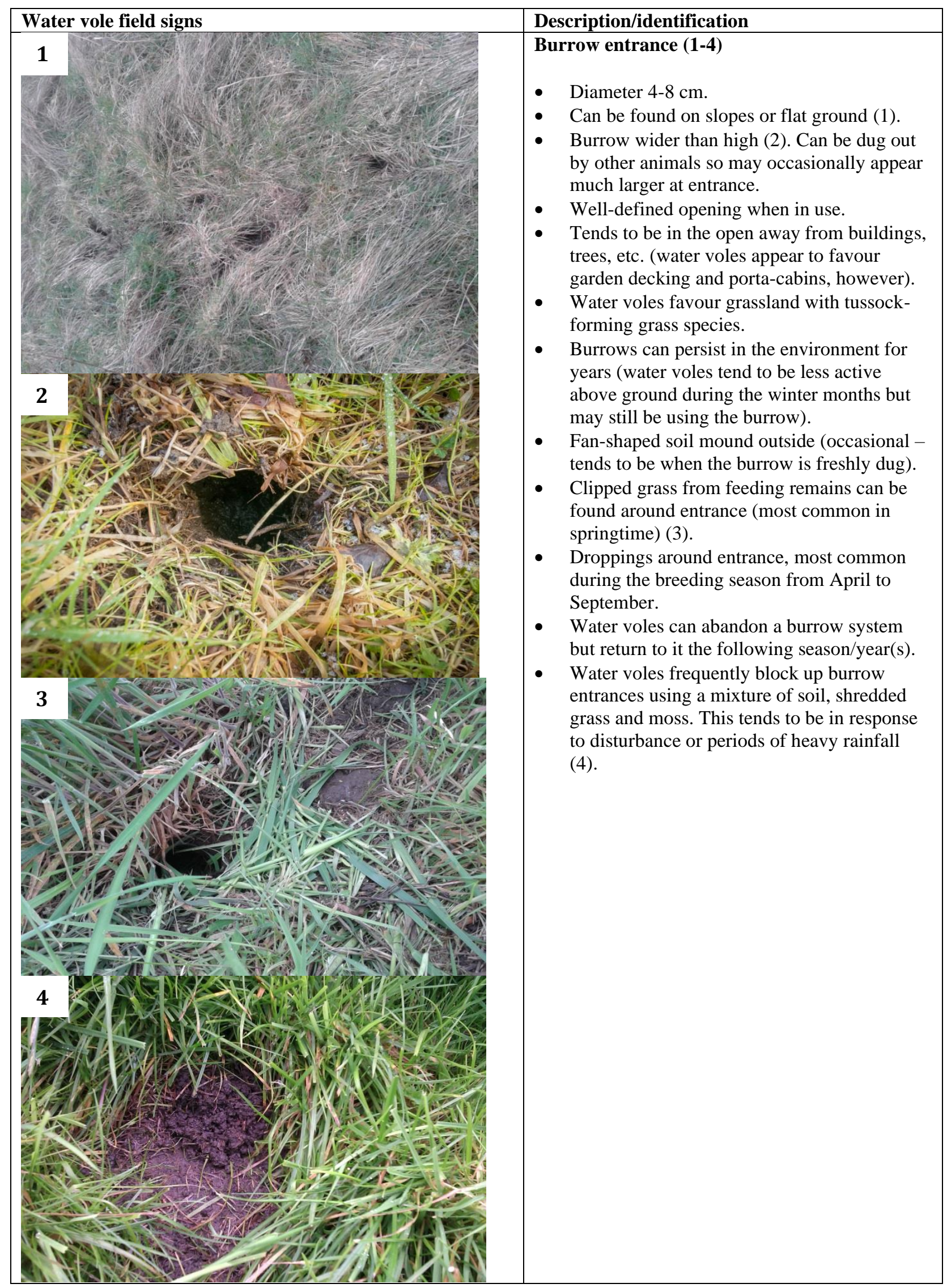




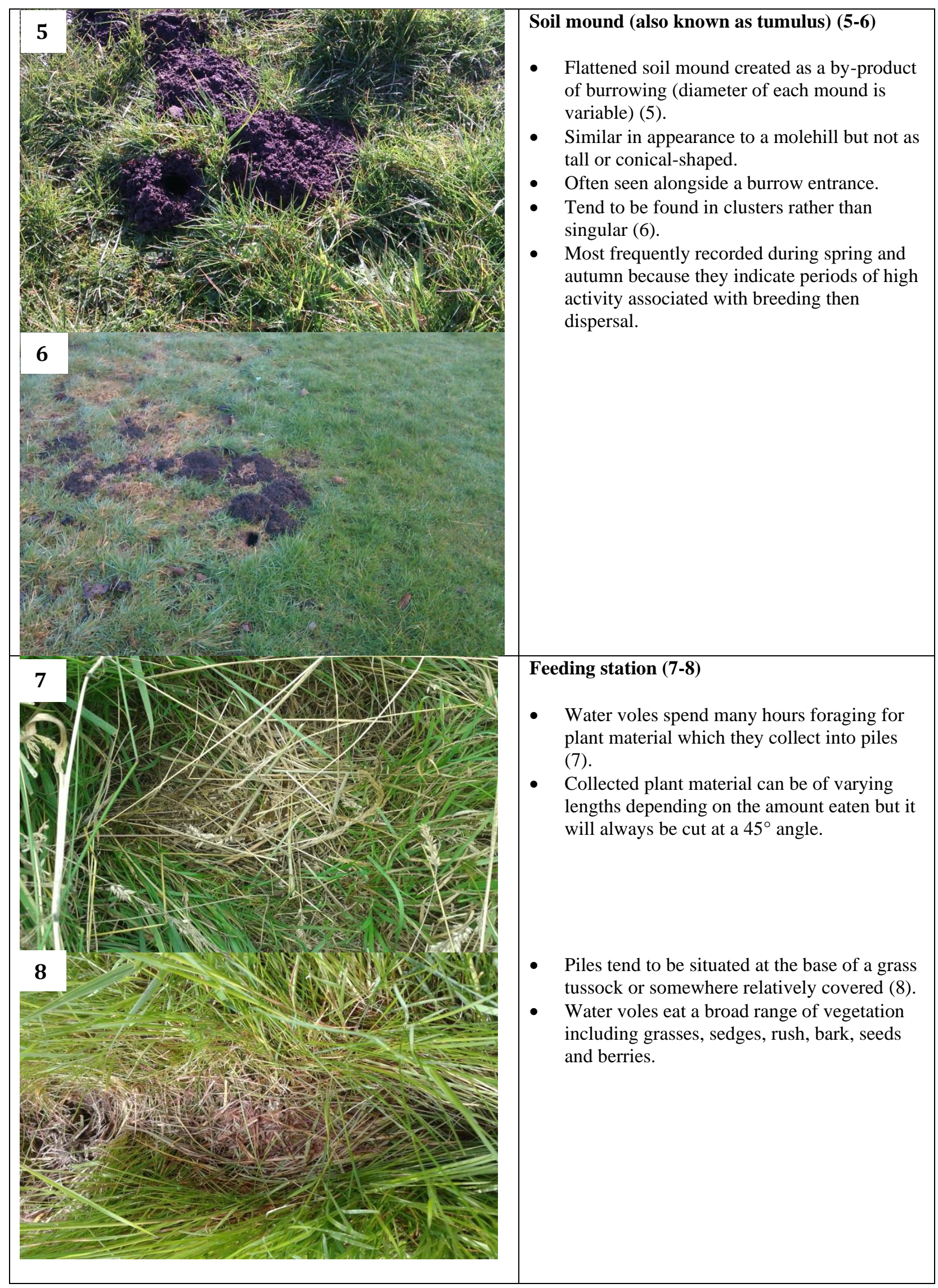




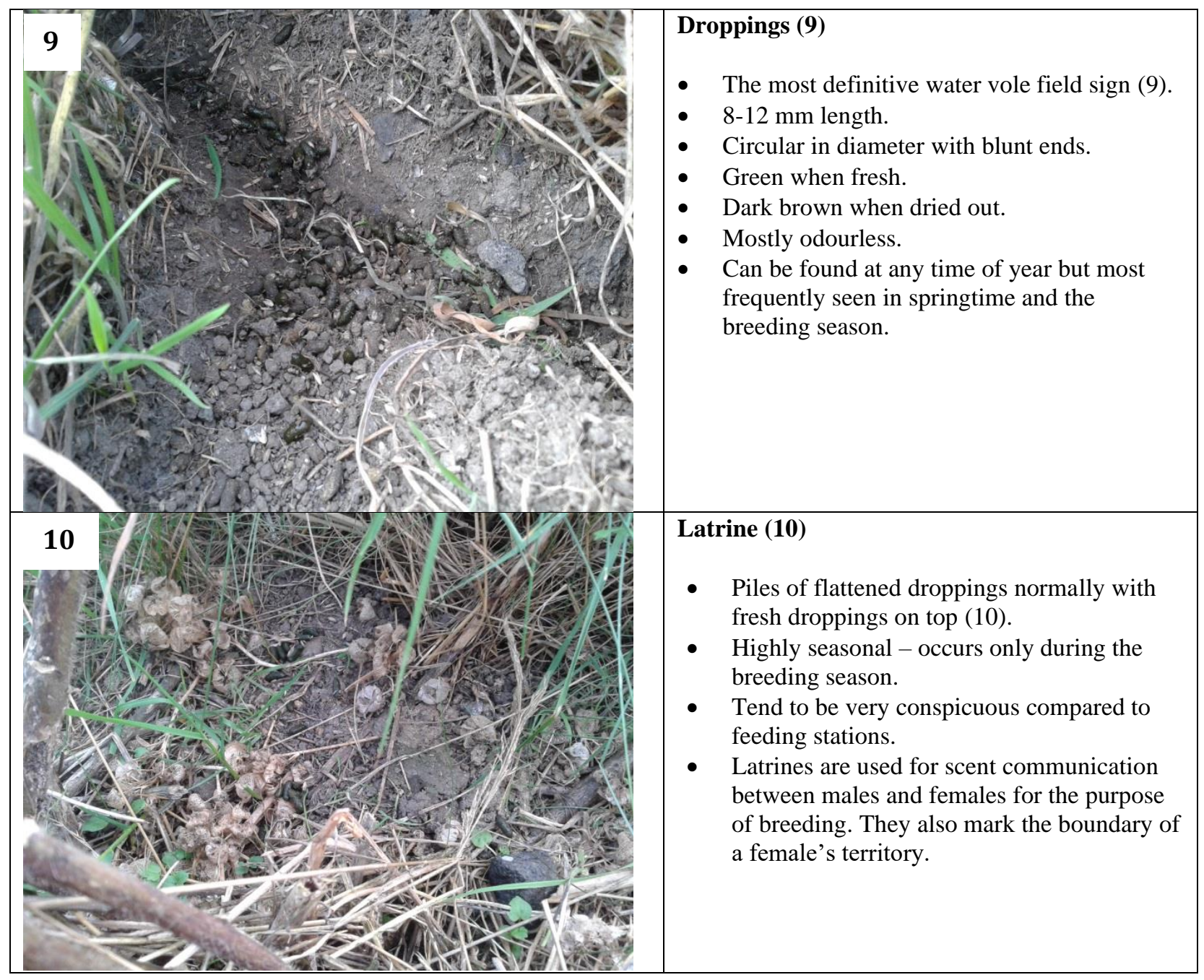

